\title{
EVALUATING THE APPLICATION OF DIVERGING DIAMOND INTERCHANGE IN ATHENS, ALABAMA
}

\author{
Tahmina Khan ${ }^{1}$, Michael Anderson ${ }^{2}$ \\ ${ }^{1,2}$ Civil and Environmental Engineering Department, University of Alabama in Huntsville, Alabama, \\ United States
}

Received 5 July 2015; accepted 17 February 2016

\begin{abstract}
A diverging diamond interchange (DDI), a freeway and arterial interchange design, uses crossovers at the ramp intersections to eliminate conflicts between arterial through traffic and the left turning traffic from both the arterial and the ramps. The conventional diamond interchange (CDI) compared with the DDI has similar on-ramps and off-ramps, but there is a change in the number of lanes on the arterial. A case study has been conducted for an interchange in Athens, Alabama. The existing interchange is a conventional diamond interchange which is compared with a DDI built at the same location by using Synchro/ Simtraffic as a simulation tool. The analysis focused on determining level of service and vehicle delay for the two interchange types. In this project effort was made to know if a DDI is the right solution for all interchange locations through the examination of a single location and adjustments to traffic volumes under numerous combination of turning movement scenarios where variation of capacity and the influence of proximity of adjacent intersections were also included. Finally, it was concluded that DDI cannot be an appropriate measure to improve the current CDI network for the study area since only 4 special cases it performs better than CDI. And DDI cannot be the effective traffic calming measure if it is associated with upstream or downstream intersections.
\end{abstract}

Keywords: conventional diamond interchange, diverging diamond interchange, traffic simulation, delay.

\section{Introduction}

A diverging diamond interchange (DDI), a freeway and arterial interchange design, uses crossovers at the ramp intersections (500 $\mathrm{ft}$ apart (Bared et al., 2005)) to eliminate conflicts between arterial through traffic and the left turning traffic from both the arterial and the ramps. The traffic switches from right side to left side at the crossovers. This allows unopposed left turns from the arterial to the ramps. These two crossovers can act as a traffic-calming device. The advisory speed on approach to the DDI and DDI-M
(DDI-Minimal) crossovers was $40 \mathrm{~km} / \mathrm{h}(25$ $\mathrm{mi} / \mathrm{h}$ ) (Technology, 2013).

Two on-ramps and two off-ramps that connect the crossroad and the freeway, have left turn and right turn lanes. The arterial has one through lane, one through plus left-turn lane, and one dedicated right-turn lane. The DDI operates as a two-phase signal with only one direction of travel on the cross route allowed through at a time. When considering a DDI with a signalized intersection close to the interchange, other interchange types should also be considered (Transportation, 2010).

${ }^{1}$ Corresponding author: tk0002@uah.edu

jitte 38 
The conventional diamond interchange compared with the DDI has similar on-ramps and off-ramps, but there is a change in the number of lanes on the arterial. It has two through lanes, one dedicated left-turn lane, and one dedicated right-turn lane. Clearly, the section between the ramps needs more right-of-way as compared with the DDI (two extra left-turn lanes). There are two signals at $\mathrm{A}$ and $\mathrm{B}$, and the distance between ramps is also $500 \mathrm{ft}$ (Transportation, 2010).

In this project effort is made to know if a DDI is the right solution for all interchange locations through the examination of a single locations and adjustments to traffic volumes. A case study has been conducted for an interchange in Athens, Alabama. The existing interchange is a conventional diamond interchange which is compared with a DDI built at the same location. The analysis focuses on determining level of service and vehicle delay for the two interchange types. This study is carried out using Synchro/ Simtraffic as a simulation tool.

\section{Literature Review}

The DDI was first introduced in a 2003 paper by Chlewicki that explored how the interchange functions and reported on a simulation study at one location for one turning movement volume scenario, the existing conventional diamond interchange (CDI) (Chlewicki, 2003). Sharma and Chatterjee (2007) used a method similar to the method used by Bared et al. (2005) with slightly more than a dozen new traffic volume combinations. Afshar et al. (2009) compared the DDI with the single point urban interchange (SPUI) in 10 traffic volume combinations.
In 2007, the Federal Highway Administration has modeled the Springfield, Missouri DDI to evaluate the human factor aspects of the proposed design and concludes that driver confusion will not be an issue if the DDI were designed, rather DDI would be a safer interchange because of its fewer conflict points (Chlewicki, 2011) than a conventional diamond interchange. The Federal Highway Administration has also released a technical brief covering four intersection designs and two interchange designs that offer substantial advantages of conventional at-grade intersections and grade-separated diamond interchanges (Hughes and Jagannathan, 2009).

Chilukuri et al. (2011) have conducted a performance evaluation of the diverging diamond interchange at Springfield, MO. The evaluation assessed traffic operations, safety, and public perceptions. Other researchers have been studying various aspects of DDI including construction, operation and application (Xu et al., 2011; Chlewicki, 2011).

Anderson et al. (2011) have developed an initial Process- Model of the Diverging Diamond Interchange. This paper evaluated the following factors that affect traffic through a DDI: traffic volume, length of time traffic light is green, and the criteria for changing the traffic signal.

In June 2009, the first DDI in the United States was opened to traffic at the I-44 and SR-13 interchange in Springfield, Missouri that took just 6 months and cost over $\$ 3$ million and was chosen as one of the best new engineering innovations of 2009 by Popular Science magazine in terms of safety 
and efficiency perspectives (Chilukuri et al., 2011). In July 2010, a second DDI was opened to traffic in Springfield. DDIs were also opened to traffic in the St. Louis, Missouri, area and American Fork, Utah, in the second half of 2010 (Transportation, 2010).

Advantages with the DDI are as follows (Transportation, 2010; Wolf, 2009):

- Reduces the conflict points, the number phases to two with shorter cycle lengths and reduces delays.

- Increases the sight distance and reduces off road crashes.

- Improves pedestrian safety.

- Facilitates heavy left-turn movements more efficiently and also makes a wrong way entry onto freeway ramps extremely difficult.

Can be more cost and time-effective to build $(75 \%$ cost saving over alternative design), as they often require less land and fewer potentially-costly changes to existing road structures (ATS/American, n.d.). For example:

- For a retrofit:

- Existing bridge can usually be used;

- Additional right-of-way rarely needed;

- Construction time is reduced;

- Maintenance of traffic is simplified during construction;

- For a new interchange:

- Fewer lanes than other interchange forms;

- Less bridge structure;

- Less right-of-way than a cloverleaf form.

Disadvantages to be considered are (Transportation, 2010; Wolf, 2009):
- It is not applicable when current or projected through volumes are high.

- The drivers inconvenienced the most by the installation of a DDI are those going through on the cross route because they must crossover to the left side of the road and then back again to reach their destination.

- The crossover maneuver is not intuitive because drivers travel on the opposite side of the road.

- The existing traffic cannot re-enter, once taken a wrong direction. It has to leave the intersection and again get on the intersection because of which emergency management cannot use exit and entrance ramps.

- Signalized intersections close to a DDI can complicate its operation due to signal timing issues. DDIs may not work well when adjacent intersections on the cross route are closely located and experience heavy traffic themselves.

\section{Study Area}

The interchange chosen for this case study is a conventional diamond interchange (CDI) at Athens, Alabama. Athens is a city in Limestone County, in the U.S. state of Alabama. As of the 2010 U.S. Census, the population of the city is 21,897 . The conventional diamond interchange in Athens is where US 72 passes over I-65. A print screen of the Google maps is shown in Fig. 1. Majority of the traffic flows through east bound and west bound. There is little business around the interchange but that doesn't quite affect the traffic. Lot of the traffic is observed only during the morning and the evening peak hour. Most of the traffic on the through traffic observed is the trips made in and out of Huntsville, Alabama. 


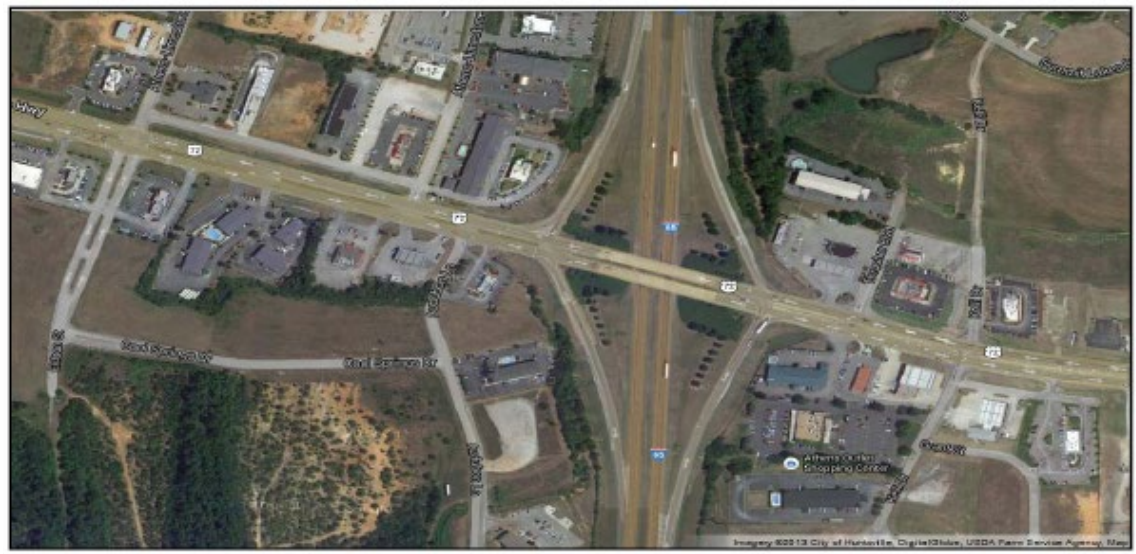

Fig. 1.

Picture of Conventional Diamond Interchange at Athens, Alabama Source: Screenshot of Google Map

\section{Simulation Tool}

Traffic simulation models can be applied to study complex situations when analytic approaches may not be appropriate or to test alternative scenarios in the computer, without altering the actual system, which may be very costly and/or unsafe. Simulation methods are advantageous in conducting "what if" studies and testing the scenarios and phenomena that may not occur or are hard to capture in the field (Xu et al., 2011). Because of these major advantages, simulation has become an essential tool in traffic operational analysis (Jones et al., 2004). There are a variety of simulation tools available for studying diverging diamond interchange. Capabilities and functions of these different simulation tools differ widely. Selecting an appropriate simulation model would depend on the characteristics of the site/interchange, objective of the study, ease and familiarity of the user with the model. SimTraffic/Synchro is being used to analyze the interchanges considered for this study.

\subsection{SimTraffic/Synchro}

SimTraffic is a microscopic simulation package which uses the outputs of Synchro program to model street networks. SimTraffic is the traffic simulation portion of the Synchro software package. The Synchro software package performs intersection analysis using the Highway Capacity Manual methods, as well as ICU. SimTraffic was originally developed for modeling and optimizing traffic signal timings. The capabilities of the software were improved in its subsequent versions which made it a full-function simulation package. SimTraffic has being used for this study for its ease to use; it's shorted coding times even for inexperienced users.

\section{Methodology}

An operational analysis should be conducted whenever a DDI is considered. Operational measures such as level of service (LOS), delay and capacity can be used to assess 
the operational characteristics of a DDI. The operational analysis can also be used to determine the number of lanes and the configuration needed for the DDI to operate acceptably. Micro-simulation models can also be used to create animations which can be used to better understand the benefits and concept of DDI at a particular location. The following steps were followed in development of the simulation model.

- Data collection;

- Network coding and debugging;

- Simulation of the models.

\subsection{Data Collection}

Required data inputs for the simulation model includes classified vehicle volumes for each direction, road geometrics, signal timing, posted speed limits, peak hour factors. The traffic volumes are collected by counting the vehicles manually for low volume movements and electronic counting board is used for heavy movements. The traffic is classified into two categories one is passenger car units and second is trucks. All the vehicles with more than 3 axels where classified to be a truck in this project.

Manual counts are typically used for periods of less than a day. Normal intervals for a manual count are 5,10 , or 15 minutes. Traffic counts during a Monday morning rush hour and a Friday evening rush hour may show exceptionally high volumes and are not normally used in analysis; therefore, counts are usually conducted on a Tuesday, Wednesday, or Thursday. Hence the traffic count was conducted on Thursday. The temperature at the time of collection was $46 \mathrm{~F}$ with zero precipitation. The traffic count was done for a 15 minute interval for an hour. The time chosen to perform the count was the morning peak hour i.e. 7:00 am to 8:00 am.
The west bound through traffic had a total volume of 1050 and it was the highest volume for the entire interchange. The east bound through, west bound through and east bound right movements had more traffic than other directions. The turning movement volumes were not much for this conventional diamond interchange. The cycle length for one of the signals is 112 seconds. The posted speed limits for this interchange are $45 \mathrm{mph}$. The peak hour factors for each direction are calculated using the peak hour factor formula.

\subsection{Network Coding and Debugging}

SimTraffic allows importing an aerial photo and drawing the network on top of it, eliminating the need to measure coordinates, links and turn bay lengths. Image types such as .jpg, .gif, .tif can be imported (Husch and Albeck, 2006).

The current interchange with the current volumes and other parameters is first coded to understand the current scenario. Therefore an aerial picture of the conventional diamond interchange (CDI) was saved into jpg format and was imported as a background file in Synchro. The word coordinates where set so that the measurements in the Synchro match the original measurements of the design in Athens. After setting the world coordinates the network is drawn using the links in the software. The network built on the background is very much close to the real world scenario. The number of lanes and geometric information is given in the Lane Settings Window. The west bound left (WBL) lane and east bound left (EBL) lane is given a storage length of $150 \mathrm{ft}$. After all the geometrics are given, the network can be shown in Fig. 2 . 


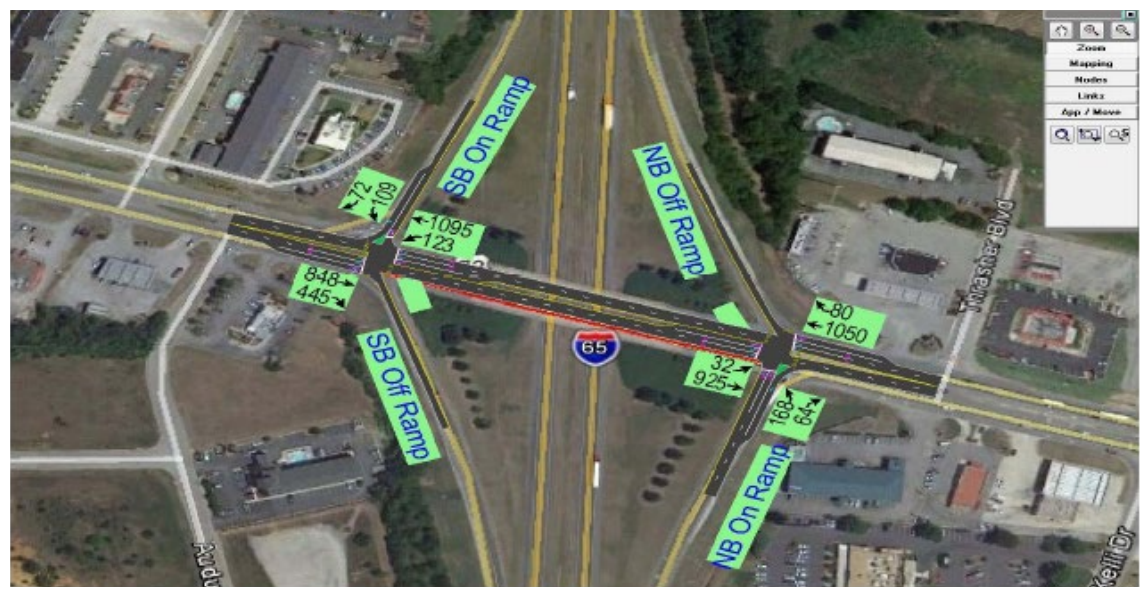

Fig. 2.

Picture of the CDI with Morning Peak Hour Traffic after Coding in Synchro

The Volume Settings Window displays a grid in which the vehicle volume information can be given. The traffic volumes are entered for each movement in vehicles per hour. Synchro models the hourly volumes provided for one design period (Husch and Albeck, 2006).

The peak hour factor calculated is not used for the simulation because the PHF values are different for each direction which may cause imbalance in the volumes. The PHF for the total volumes for entire interchange for one hour was calculated to be 0.90 . Hence all the networks coded in this project have a PHF of 0.90.

The heavy vehicles (\%) under the volumes settings represent the percentage of trucks and buses for each traffic movement. Though the truck volumes were collected at the time of data collection this value is left unchanged. The default value for this field is $2 \%$.

Most of the coding is done in Timing Window, which is one of the four main input windows. Phase numbers and detector locations for actuated signals are automatically assumed by Synchro. Its ability to assume default values for a number of parameters were found to reduce network coding time and still provide some functionality. Under Timing Settings Window the turn type is set according to the type of turn that existed in the CDI. Types of left turn movements coded in Synchro are Permitted, Protected and Permitted plus Protected and type of right turn movements given in Synchro is Free that should only be used if the movement has an acceleration lane downstream (Husch and Albeck, 2006).

After completion of coding, the model developed in SimTraffic was run for the existing cycle length of 112 seconds and for the optimized cycle length of 40 seconds determined by Synchro by using the Node Settings Window.

The DDI to be compared with the optimized CDI and current scenario CDI is also coded in Synchro. A similar method is followed to develop this model. To better understand the geometrics of a DDI the DDI at Springfield, Missouri was studied. The lane setting, turn 
movements and other parameters are given according to DDI geometrics. The PHF is the same as other interchanges i.e. 0.90. The cycle lengths are optimized for the DDI. The vehicle volumes are same as collected. The DDI modeled in the same site looks as in Fig. 3.

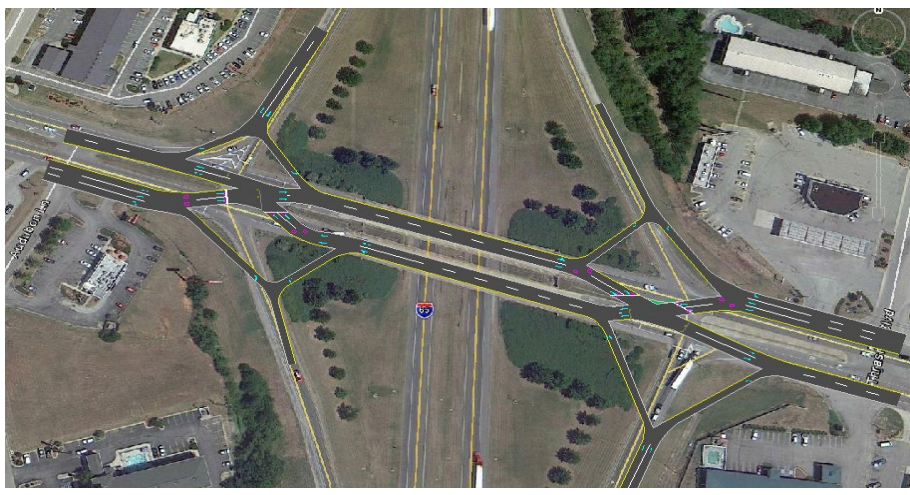

Fig. 3.

DDI Model for Athens in Synchro

Debugging is nothing but eliminating error that will prevent a simulation from running. Debugging a network may sometimes still leave the network with incorrect roadway geometric, traffic volumes which must be detected by user. Debugging complex networks may take substantial time to reach the point where the model will run. Debugging is different from validation. SimTraffic detects errors by referencing them by node number, directional approach and turn movement making it easy for identification. The developed models did not have any errors (Husch and Albeck, 2006).

The computations performed cannot be expected to be extremely accurate, and the final results must be considered as estimates that are accurate and precise only within the limits of the input values used.

\subsection{Simulations on Isolated DDI/CDI Cases}

Based on the results of increasing-decreasing scenarios of previously developed models, it was concluded that CDI performs better with increase in volumes and can be a good option for interchanges with very high turning volumes as well.

To evaluate the application of DDI, further simulations are must to carry out at approach level by intersection. Moreover, a numerous number of scenarios are required to assess the approach delay of CDI and DDI by varying the capacity. The goal is to summarize the results by the type of interchange after running all options and select few scenarios to perform another analysis where CDI or DDI was not be in isolation.

Models Preparation: The following models were selected under isolated condition for further assessment:

- DI one lane model;

- DI two-lane model;

- DDI one lane model;

- DDI two-lane model.

These models were built in Synchro upon considering previously collected data. 
Network coding and debugging were done to reflect the anticipated condition by eliminating unnecessary errors of the models.

Analyses: A number of scenarios were formulated in such a way that involves less dependency among turning volumes, greater influence on delay and uniqueness. Table 1 presents a total of 83 scenarios and each of those was run for $0 \%, 50 \%, 100 \%, 150 \%$ and $200 \%$ increments of existing traffic. It can be noted that internal turning movements were calculated and adjusted for several scenarios when it was obvious since there is no driveways in between two intersections.

\section{Table 1}

\section{List of Scenarios ${ }^{2}$}

\begin{tabular}{|c|c|}
\hline No & Scenario \\
\hline 1 & 1a - Int1(SBL+EBT+WBT+WBL), Int2(EBT+EBL+NBL+WBT) \\
\hline 2 & $1 \mathrm{~b}-\mathrm{Int} 1(\mathrm{SBL}+\mathrm{EBT}), \operatorname{Int} 2(\mathrm{NBR}+\mathrm{EBT}+\mathrm{EBL})$ \\
\hline 3 & $1 \mathrm{c}-\operatorname{Int} 1(\mathrm{SBL}+\mathrm{EBT}), \operatorname{Int} 2(\mathrm{WBR}+\mathrm{EBL}+\mathrm{EBT})$ \\
\hline 4 & 1d - Int1(SBL+EBT+WBT+WBL), Int2(NBR+WBT+NBL+EBT+EBL) \\
\hline 5 & $1 \mathrm{i}-\operatorname{Int} 1(\mathrm{SBL}+\mathrm{EBT}), \mathrm{Int} 2(\mathrm{EBT}+\mathrm{EBL})$ \\
\hline 6 & 1J - Int1(SBL+EBT+WBT+WBL), Int2(EBT+EBL+WBR+WBT+NBL) \\
\hline 7 & $2 \mathrm{a}-\operatorname{Int} 1(\mathrm{SBR}+\mathrm{WBT}+\mathrm{WBL}), \operatorname{Int} 2(\mathrm{WBT}+\mathrm{NBL})$ \\
\hline 8 & $2 \mathrm{~b}-\mathrm{Int} 1(\mathrm{SBR}+\mathrm{WBT}+\mathrm{WBL}+\mathrm{EBT}+\mathrm{SBL}), \mathrm{Int} 2(\mathrm{WBT}+\mathrm{NBL}+\mathrm{NBR}+\mathrm{EBT}+\mathrm{EBL})$ \\
\hline 9 & 2c - Int1 $(S B R+W B T+W B L+E B T+S B L), I n t 2(W B T+N B L+W B R+E B L+E B T)$ \\
\hline 10 & $2 \mathrm{e}-\mathrm{Int} 1(\mathrm{SBR}+\mathrm{WBT}+\mathrm{WBL}), \operatorname{Int} 2(\mathrm{WBT}+\mathrm{NBL}+\mathrm{NBR})$ \\
\hline 11 & $2 \mathrm{f}-\mathrm{Int} 1(\mathrm{SBR}+\mathrm{WBT}+\mathrm{WBL}+\mathrm{EBT}+\mathrm{SBL}), \mathrm{Int} 2(\mathrm{WBT}+\mathrm{NBL}+\mathrm{EBL}+\mathrm{EBT})$ \\
\hline 12 & $2 \mathrm{~g}-\operatorname{Int} 1(\mathrm{SBR}+\mathrm{WBT}+\mathrm{WBL}), \operatorname{Int} 2(\mathrm{WBT}+\mathrm{NBL}+\mathrm{WBR})$ \\
\hline 13 & 3a - Int1 (EBR+WBL+WBT), Int2(WBT+NBL) \\
\hline 14 & $3 \mathrm{~b}-\mathrm{Int} 1(\mathrm{EBR}+\mathrm{WBL}+\mathrm{WBT}+\mathrm{EBT}+\mathrm{SBL}), \mathrm{Int} 2(\mathrm{WBT}+\mathrm{NBL}+\mathrm{NBR}+\mathrm{EBT}+\mathrm{EBL})$ \\
\hline 15 & $3 c-$ Int1 $(\mathrm{EBR}+\mathrm{WBL}+\mathrm{WBT}+\mathrm{EBT}+\mathrm{SBL}), \mathrm{Int} 2(\mathrm{WBT}+\mathrm{NBL}+\mathrm{WBR}+\mathrm{EBL}+\mathrm{EBT})$ \\
\hline 16 & $3 \mathrm{e}-\mathrm{Int} 1(\mathrm{EBR}+\mathrm{WBL}+\mathrm{WBT})$, Int2(WBT+NBL+NBR) \\
\hline 17 & $3 \mathrm{f}-\operatorname{Int} 1(\mathrm{EBR}+\mathrm{WBL}+\mathrm{WBT}+\mathrm{EBT}+\mathrm{SBL}), \mathrm{Int} 2(\mathrm{WBT}+\mathrm{NBL}+\mathrm{EBL}+\mathrm{EBT})$ \\
\hline 18 & $3 g-\operatorname{Int1}(\mathrm{EBR}+\mathrm{WBL}+\mathrm{WBT}), \operatorname{Int} 2(\mathrm{WBT}+\mathrm{NBL}+\mathrm{WBR})$ \\
\hline 19 & $5 \mathrm{~b}-$ Int1 $(\mathrm{SBR}+\mathrm{EBT}+\mathrm{SBL}), \mathrm{Int} 2(\mathrm{NBR}+\mathrm{EBT}+\mathrm{EBL})$ \\
\hline 20 & Sc - Int1(SBR+EBT+SBL), Int2(WBR+EBL+EBT) \\
\hline 21 & Se - Int1(SBR), Int2(NBR) \\
\hline 22 & $5 \mathrm{~g}-\operatorname{Int} 1(\mathrm{SBR}), \operatorname{Int} 2(\mathrm{WBR})$ \\
\hline 23 & $5 \mathrm{i}-\mathrm{Int} 1(\mathrm{SBR}+\mathrm{EBT}+\mathrm{SBL}), \mathrm{Int} 2(\mathrm{EBT}+\mathrm{EBL})$ \\
\hline 24 & $7 \mathrm{~b}-\operatorname{Int} 1(\mathrm{EBR}+\mathrm{EBT}+\mathrm{SBL}), \operatorname{Int} 2(\mathrm{NBR}+\mathrm{EBT}+\mathrm{EBL})$ \\
\hline 25 & 7c - Int1(EBR+EBT+SBL), Int2(WBR+EBL+EBT) \\
\hline 26 & $7 \mathrm{e}-$ Int $1(\mathrm{EBR})$, Int $2(\mathrm{NBR})$ \\
\hline 27 & $7 \mathrm{~g}-\operatorname{Int} 1(\mathrm{EBR}), \mathrm{Int} 2(\mathrm{WBR})$ \\
\hline 28 & $7 \mathrm{i}-\mathrm{Int} 1(\mathrm{EBR}+\mathrm{EBT}+\mathrm{SBL}), \mathrm{Int} 2(\mathrm{EBT}+\mathrm{EBL})$ \\
\hline 29 & $9 \mathrm{a}-\operatorname{Int} 1(\mathrm{WBT}+\mathrm{WBL}), \operatorname{Int} 2(\mathrm{WBT}+\mathrm{NBL})$ \\
\hline 30 & $9 \mathrm{e}-\operatorname{Int} 1(\mathrm{WBT}+\mathrm{WBL}), \operatorname{Int} 2(\mathrm{WBT}+\mathrm{NBL}+\mathrm{NBR})$ \\
\hline 31 & $9 \mathrm{~g}-\operatorname{Int} 1(\mathrm{WBT}+\mathrm{WBL}), \operatorname{Int} 2(\mathrm{WBT}+\mathrm{NBL}+\mathrm{WBR})$ \\
\hline 32 & $11 \mathrm{e}-\operatorname{Int} 1(\mathrm{SBR}+\mathrm{EBR}), \operatorname{Int} 2(\mathrm{NBR})$ \\
\hline 33 & $11 \mathrm{~g}-\operatorname{Int} 1(\mathrm{SBR}+\mathrm{EBR})$, Int2(WBR) \\
\hline 34 & $12 \mathrm{e}-\operatorname{Int} 1(\mathrm{SBR}), \operatorname{Int} 2(\mathrm{NBR}+\mathrm{WBR})$ \\
\hline 35 & $12 \mathrm{~g}-$ Int1(EBR), Int2(NBR+WBR) \\
\hline 36 & $6 \mathrm{~b}-\operatorname{Int} 1(\mathrm{EBT})$, Int2(NBR+WBR+WBT) \\
\hline 37 & $6 \mathrm{c}-\operatorname{Int} 1(\mathrm{EBT}), \operatorname{Int} 2(\mathrm{NBL}+\mathrm{EBL})$ \\
\hline
\end{tabular}

${ }^{2}$ Where, Int 1 is the leftmost intersection and Int 2 is the rightmost intersection of each model and different turning movement combinations presented in parentheses are as follows:

SBL, SBT, SBT - Southbound Left, Southbound Through, Southbound Right

NBL, NBT, NBT - Northbound Left, Northbound Through, Northbound Right

WBL, WBT, WBT - Westbound Left, Westbound Through, Westbound Right

EBL, EBT, EBT - Eastbound Left, Eastbound Through, Eastbound Right 


\begin{tabular}{|c|c|}
\hline No & Scenario \\
\hline 38 & 6d - Int1(EBT), Int2(NBL+EBL+WBT) \\
\hline 39 & $6 e-\operatorname{Int1}(\mathrm{EBT}), \operatorname{Int} 2(\mathrm{NBR}+\mathrm{WBR}+\mathrm{NBL}+\mathrm{EBL})$ \\
\hline 40 & 6f - Int1(SBR+EBR+EBT), Int2(WBT) \\
\hline 41 & $6 \mathrm{~h}-\operatorname{Int} 1(\mathrm{SBR}+\mathrm{EBR}+\mathrm{EBT}), \operatorname{Int} 2(\mathrm{NBL}+\mathrm{EBL})$ \\
\hline 42 & $6 \mathrm{i}-\mathrm{Int} 1(\mathrm{SBR}+\mathrm{EBR}+\mathrm{EBT})$, Int2(NBL+EBL+WBT) \\
\hline 43 & $6 j-$ Int1 $(S B R+E B R+E B T)$, Int2(NBR+WBR+NBL+EBL $)$ \\
\hline 44 & $8 \mathrm{a}-\operatorname{Int1}(\mathrm{SBL}+\mathrm{WBL})$, Int2(WBT) \\
\hline 45 & $8 \mathrm{~b}-\operatorname{Int} 1(\mathrm{SBL}+\mathrm{WBL}), \operatorname{Int} 2(\mathrm{NBR}+\mathrm{WBR}+\mathrm{WBT})$ \\
\hline 46 & $8 \mathrm{~d}-\operatorname{Int} 1(\mathrm{SBL}+\mathrm{WBL}), \operatorname{Int} 2(\mathrm{NBL}+\mathrm{EBL}+\mathrm{WBT})$ \\
\hline 47 & $8 \mathrm{e}-\operatorname{Int} 1(\mathrm{SBL}+\mathrm{WBL}), \operatorname{Int} 2(\mathrm{NBR}+\mathrm{WBR}+\mathrm{NBL}+\mathrm{EBL})$ \\
\hline 48 & $8 f-\operatorname{Int} 1(\mathrm{SBL}+\mathrm{WBL}+\mathrm{EBT}), \operatorname{Int} 2(\mathrm{WBT})$ \\
\hline 49 & $8 \mathrm{~g}-\operatorname{Int} 1(\mathrm{SBL}+\mathrm{WBL}+\mathrm{EBT}), \operatorname{Int} 2(\mathrm{NBR}+\mathrm{WBR}+\mathrm{WBT})$ \\
\hline 50 & $8 \mathrm{~h}-\operatorname{Int} 1(\mathrm{SBL}+\mathrm{WBL}+\mathrm{EBT}), \operatorname{Int} 2(\mathrm{NBL}+\mathrm{EBL})$ \\
\hline 51 & $8 j-$ Int $1(S B L+W B L+E B T)$, Int2(NBR+WBR+NBL+EBL) \\
\hline 52 & 10a - Int1(SBR+EBR+SBL+WBL), Int2(WBT) \\
\hline 53 & $10 \mathrm{~b}-\operatorname{Int} 1(\mathrm{SBR}+\mathrm{EBR}+\mathrm{SBL}+\mathrm{WBL}), \operatorname{Int} 2(\mathrm{NBR}+\mathrm{WBR}+\mathrm{WBT})$ \\
\hline 54 & $10 c-\operatorname{Int} 1(\mathrm{SBR}+\mathrm{EBR}+\mathrm{SBL}+\mathrm{WBL}), \operatorname{Int} 2(\mathrm{NBL}+\mathrm{EBL})$ \\
\hline 55 & 10d - Int1(SBR+EBR+SBL+WBL), Int2(NBL+EBL+WBT) \\
\hline 56 & $10 f-\operatorname{Int1}(\mathrm{SBR}+\mathrm{EBR}+\mathrm{SBL}+\mathrm{WBL}+\mathrm{EBT}), \operatorname{Int} 2()$ \\
\hline 57 & $10 \mathrm{~g}-\operatorname{Int} 1(), \operatorname{Int} 2(\mathrm{NBR}+\mathrm{WBR}+\mathrm{NBL}+\mathrm{EBL}+\mathrm{WBT})$ \\
\hline 58 & 10h - Int1(EBT), Int2(NBR+WBR+NBL+EBL+WBT) \\
\hline 59 & $10 \mathrm{i}-\operatorname{Int} 1(\mathrm{SBR}+\mathrm{EBR}+\mathrm{EBT}), \operatorname{Int} 2(\mathrm{NBR}+\mathrm{WBR}+\mathrm{NBL}+\mathrm{EBL}+\mathrm{WBT})$ \\
\hline 60 & $10 j-\operatorname{Int} 1(\mathrm{SBL}+\mathrm{WBL}), \operatorname{Int} 2(\mathrm{NBR}+\mathrm{WBR}+\mathrm{NBL}+\mathrm{EBL}+\mathrm{WBT})$ \\
\hline 61 & $13 a-\operatorname{Int} 1(\mathrm{SBL}+\mathrm{WBL}+\mathrm{EBT}), \operatorname{Int} 2(\mathrm{NBR}+\mathrm{WBR}+\mathrm{NBL}+\mathrm{EBL}+\mathrm{WBT})$ \\
\hline 62 & $13 \mathrm{~b}-\operatorname{Int1}(\mathrm{SBR}+\mathrm{EBR}+\mathrm{SBL}+\mathrm{WBL}), \operatorname{Int} 2(\mathrm{NBR}+\mathrm{WBR}+\mathrm{NBL}+\mathrm{EBL}+\mathrm{WBT})$ \\
\hline 63 & $13 c-\operatorname{Int} 1(\mathrm{SBR}+\mathrm{EBR}+\mathrm{SBL}+\mathrm{WBL}+\mathrm{EBT}), \operatorname{Int} 2(\mathrm{WBT})$ \\
\hline 64 & $13 \mathrm{~d}-\operatorname{Int1}(\mathrm{SBR}+\mathrm{EBR}+\mathrm{SBL}+\mathrm{WBL}+\mathrm{EBT}), \operatorname{Int} 2(\mathrm{NBR}+\mathrm{WBR}+\mathrm{WBT})$ \\
\hline 65 & $13 e-\operatorname{Int} 1(\mathrm{SBR}+\mathrm{EBR}+\mathrm{SBL}+\mathrm{WBL}+\mathrm{EBT}), \mathrm{Int} 2(\mathrm{NBL}+\mathrm{EBL})$ \\
\hline 66 & 13f-Int1(SBR+EBR+SBL+WBL+EBT), Int2(NBL+EBL+WBT) \\
\hline 67 & $13 \mathrm{~g}-\operatorname{Int} 1(\mathrm{SBR}+\mathrm{EBR}+\mathrm{SBL}+\mathrm{WBL}+\mathrm{EBT}), \operatorname{Int} 2(\mathrm{NBR}+\mathrm{WBR}+\mathrm{NBL}+\mathrm{EBL})$ \\
\hline 68 & $4 a-\operatorname{Int} 1(\mathrm{EBT}), \operatorname{Int} 2()$ \\
\hline 69 & $4 \mathrm{~b}-\operatorname{Int} 1(\mathrm{SBR}+\mathrm{EBR}+\mathrm{EBT}), \operatorname{Int} 2()$ \\
\hline 70 & $4 c-\operatorname{Int} 1(\mathrm{SBL}+\mathrm{WBL}), \operatorname{Int} 2()$ \\
\hline 71 & $4 \mathrm{~d}-\operatorname{Int} 1(\mathrm{SBL}+\mathrm{WBL}+\mathrm{EBT}), \operatorname{Int} 2()$ \\
\hline 72 & $4 \mathrm{e}-\operatorname{Int} 1(\mathrm{SBR}+\mathrm{EBR}+\mathrm{SBL}+\mathrm{WBL}), \operatorname{Int} 2()$ \\
\hline 73 & $4 \mathrm{f}-\operatorname{Int} 1(), \operatorname{Int} 2(\mathrm{WBT})$ \\
\hline 74 & $4 \mathrm{~g}-\operatorname{Int} 1(), \operatorname{Int} 2(\mathrm{NBR}+\mathrm{WBR}+\mathrm{WBT})$ \\
\hline 75 & $4 \mathrm{~h}-\operatorname{Int} 1(), \operatorname{Int} 2(\mathrm{NBL}+\mathrm{EBL})$ \\
\hline 76 & $4 \mathrm{i}-\operatorname{Int} 1(), \operatorname{Int} 2(\mathrm{NBL}+\mathrm{EBL}+\mathrm{WBT})$ \\
\hline 77 & $4 \mathrm{j}-\operatorname{Int} 1(), \operatorname{Int} 2(\mathrm{NBR}+\mathrm{WBR}+\mathrm{NBL}+\mathrm{EBL})$ \\
\hline 78 & ALL RIGHT Turns \\
\hline 79 & EBT+WBT (ALL THRU) \\
\hline 80 & ALL Right+ ALL Thru \\
\hline 81 & ALL LEFT Turns \\
\hline 82 & ALL Right+ ALL Left \\
\hline 83 & ALL Turning Movements \\
\hline
\end{tabular}

Each model was simulated and run by scenario for $0 \%, 50 \%, 100 \%, 150 \%$ and $200 \%$ increments. Signal timings were optimized and report was saved after every run as pdf file where measures of effectiveness by approach by intersection were recorded to perform the next phase. The measure of effectiveness chosen to generate charts in excel was Total Delay/Veh (s/v) (Husch and Albeck, 2006). These charts were prepared to assess the trends of total delay of each model by scenario, by intersection and by approach. Moreover, these can provide an opportunity to compare among models in a fair and micro level. Figs. 4 and 5 show two sample charts for the study area. 


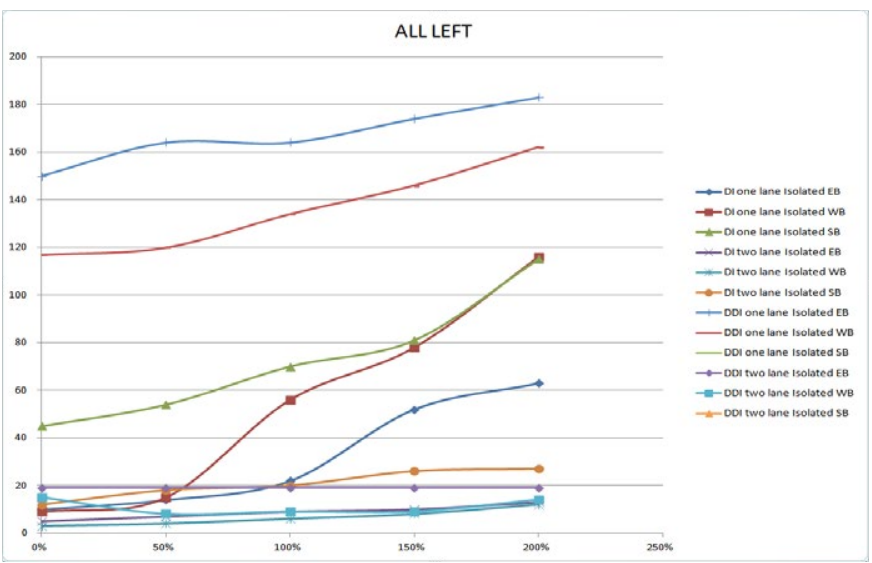

Fig. 4.

Trend of Total Delay at Intersection 1

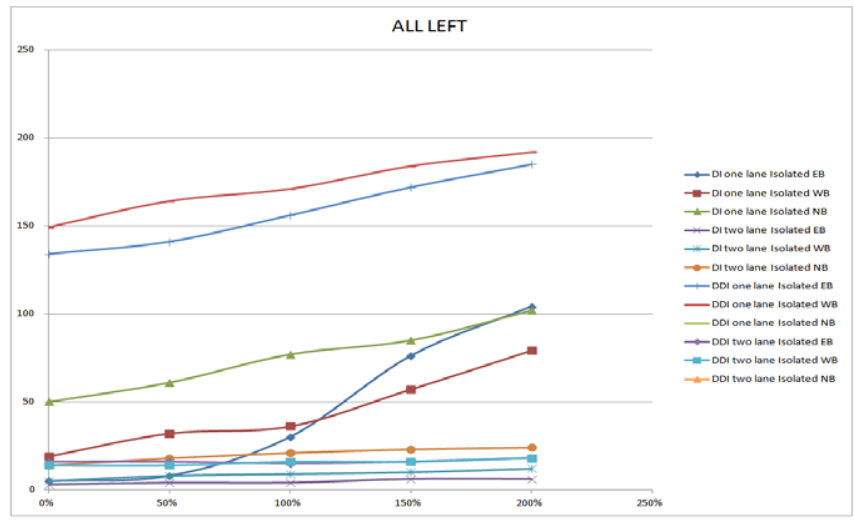

Fig. 5.

Trend of Total Delay at Intersection 2

\subsection{Results}

To summarize the qualitative assessment from charts in one table, an integer scoring method has been applied by giving each trend line a maximum 10 if it shows highest delay pattern and vice versa. It can be stated that each chart contains 10 trend lines to distinguish the delay among type of models and its approaches over the increments described above. Once the tables were completed for two intersections, those can be summed up across all scenarios by model and by approach that can give an overall picture to make a comparison between DDI and CDI. Moreover, the scenarios along the rows where DDI performs better were highlighted and chosen (shown in Table 2) for the final phase of the project.

\subsection{Discussion}

Scoring was done by qualitative judgment to find in which scenarios DDI functions better 
than CDI. And it can be seen that trend lines are not perfectly parallel to other rather those intersect among each other most of the times and pattern of trend lines changes over the increments. However, the scoring was given to track and record the scenarios where DDI operates traffic more efficiently than CDI.

\section{Further Simulations on Non Isolated DDI/CDI Cases}

Few scenarios were selected to assess the approach delay of CDI and DDI two-lane models by incorporating two additional intersections. The goal is to see how much delay traffic encounters in each type of interchange after running those scenarios.

\subsection{Models Preparation and Analyses}

Isolated models were associated with upstream and downstream intersections depending on the two spacing (500 ft and $1000 \mathrm{ft}$ ), then models were coded (shown in Figs. 6 and 7) and adjusted by eliminating errors in Synchro as usual and simulated for 8 scenarios (shown in Table 2) selected based on the above results.

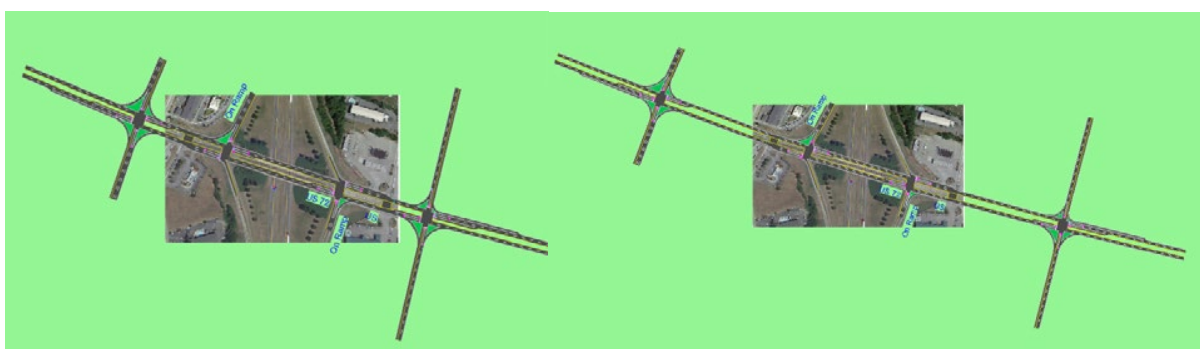

Fig. 6.

Layouts of CDI Two-Lane Model in Synchro with Two Additional Intersections, 500 and $1000 \mathrm{ft}$ Apart

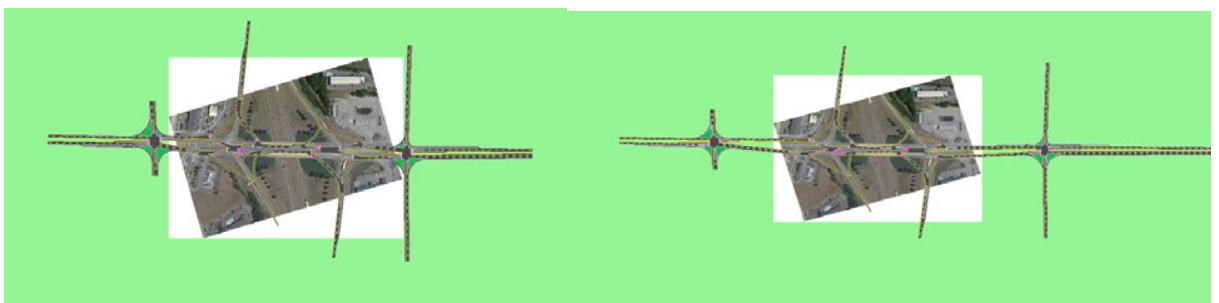

Fig. 7.

Layouts of DDI Two-Lane Model in Synchro with Two Additional Intersections, 500 and $1000 \mathrm{ft}$ Apart 
Table 2

List of Selected Scenarios

\begin{tabular}{|c|c|}
\hline No & Scenario \\
\hline 1 & ALL LEFT Turns \\
\hline 2 & ALL LEFT and ALL RIGHT Turns \\
\hline 3 & 4d - Int1(SBL+WBL+EBT), Int2() \\
\hline 4 & $4 \mathrm{e}-\operatorname{Int} 1(\mathrm{SBR}+\mathrm{EBR}+\mathrm{SBL}+\mathrm{WBL}), \operatorname{Int} 2()$ \\
\hline 5 & $4 \mathrm{~h}-\operatorname{Int} 1(), \operatorname{Int} 2(\mathrm{NBL}+\mathrm{EBL})$ \\
\hline 6 & $4 \mathrm{j}-\operatorname{Int} 1(), \operatorname{Int} 2(\mathrm{NBR}+\mathrm{WBR}+\mathrm{NBL}+\mathrm{EBL})$ \\
\hline 7 & $10 c-\operatorname{Int} 1(\mathrm{SBR}+\mathrm{EBR}+\mathrm{SBL}+\mathrm{WBL}), \operatorname{Int}(\mathrm{NBL}+\mathrm{EBL})$ \\
\hline 8 & 10f - Int1(SBR+EBR+SBL+WBL+EBT), Int2() \\
\hline
\end{tabular}

Again, each model was run by scenario (shown in Table 2) for $0 \%, 50 \%, 100 \%$, $150 \%$ and $200 \%$ increments. Signal timings were optimized as a whole by using network optimization tool in Synchro and report were saved after every run as pdf file where measures of effectiveness by approach by intersection were recorded to generate charts.

\subsection{Results}

It has been found that only scenarios $4 \mathrm{~d}$ and $10 f$ (charts drawn under the total delays of Intersection 1), and only scenarios $4 \mathrm{~h}$, and $4 j$ (charts drawn under the total delays of Intersection 2) show less delay for DDI models.

Furthermore, it has been observed in almost every case after network optimization, traffic at upstream and downstream intersections were operated under less delay for CDI network.

Table 3 presents a sample or a comparison of delay values occurred in two models.

\section{Table 3}

Total Delay for Upstream and Downstream Intersections by Scenarios at 200\% Increment

\begin{tabular}{|l|l|l|}
\hline \multirow{2}{*}{ Scenario } & Delay, CDI 500 ft network & Delay, DDI 500 ft network \\
\cline { 2 - 3 } & Upstream + Downstream & Upstream + Downstream \\
\hline ALL LEFT Turns & 55 & 57 \\
\hline ALL LEFT_ALL RGT & 101 & 147 \\
\hline $4 d-$ Int1(SBL+WBL+EBT), Int2() & 357 & 443 \\
\hline $4 e-$ Int1(SBR+EBR+SBL+WBL), Int2() & 102 & 159 \\
\hline $4 h-$ Int1(), Int2(NBL+EBL) & 55 & 59 \\
\hline $4 j-$ Int1(), Int2(NBR+WBR+NBL+EBL) & 60 & 59 \\
\hline $10 c-$ Int1(SBR+EBR+SBL+WBL), Int2(NBL+EBL) & 99 & 144 \\
\hline $10 f-$ Int1(SBR+EBR+SBL+WBL+EBT), Int2() & 480 & 596 \\
\hline
\end{tabular}




\section{Conclusions}

It can be concluded that DDI cannot be an appropriate measure to improve the current CDI network for the study area since only 4 special cases it performs better than CDI. And DDI cannot be the effective traffic calming measure if it is associated with upstream or downstream intersections.

\section{Acknowledgment}

The authors would like to acknowledge the support of Alabama Department of Transportation for the funding to conduct the research leading to this article.

\section{References}

Afshar, A.M.; Bared, J.G.; Wolf, S.; Edara, P.K. 2009. Traffic Operational Comparison of Single-Point and Diverging Diamond Interchanges. Presented at the Transportation Research Board 88th Annual Meeting, Transportation Research Board. 21 p.

Anderson, M.; Schroer, B.; Moeller, D. 2011. Simulation of the diverging diamond interchange, Huntsville, AL: UAH Research Report.

ATS/American, n.d. The Official Website of the DDI - "A Diamond Interchange With a Twist". Available from Internet: <http://www.divergingdiamond.com/ benefits.html>.

Bared,J.G.; Edara, P.K.; Jagannathan, R. 2005. Design and Operational Performance of Double Crossover Intersection and Diverging Diamond Interchange, Transportation Research Record: Journal of the Transportation Research Board, 1912: 31-38.

Chilukuri, V.; Siromaskul, S.; Trueblood, M.; Ryan, T. 2011. Diverging diamond interchange performance evaluation (I-44 \& Route 13). Available from Internet: <http://library. modot.mo.gov/RDT/reports/TRyy1013/or11012.pdf >.
Chlewicki, G. 2003. New Interchange and Intersection Designs: The Synchronized Split-Phasing Intersection and the Diverging Diamond Interchange. Anaheim, California, 2nd Urban Street Symposium.

Chlewicki, G. 2011. Should the diverging diamond interchange always be considered a diamond interchange form?, Transportation Research Record: Journal of the Transportation Research Board, 2223: 88-95.

Hughes, W.; Jagannathan, R. 2009. Double Crossover Diamond Interchange. Available from Internet: <http://www.fhwa. dot.gov/publications/research/safety/09054/09054.pdf $>$.

Husch, D.; Albeck, J. 2006. Synchro Studio 7. s.1.:Trafficware.

Jones, S.L.; Sullivan, A.J.; Cheekoti, N. 2004. Traffic Simulation Software. Available from Internet: <http:// utca.eng.ua.edu/files/2011/08/02217fnl.pdf >.

Sharma, S.; Chatterjee, I. 2007. Performance Evaluation of the Diverging Diamond Interchange in Comparison with the Conventional Diamond Interchange. Iowa State University, Ames, Transportation Scholars Conference.

Technology, F. O. o. S. R. D. a. 2013. Drivers' Evaluation of the Diverging Diamond Interchange. Available from Internet: <https://www.fhwa.dot.gov/publications/ research/safety/07048/07048.pdf $>$.

Transportation, M.D.o. 2010. Missouri's Experience with a Diverging diamond interchange - Lessons Learned. Available from Internet: <http://library.modot.mo.gov/ RDT/reports/UnNumbrd/or10021.pdf $>$.

Wolf, S. 2009. Diverging Diamond Interchange 101. Available from Internet: <http://transportation.ky.gov/us-68-doublecrossover-diamond/documents/fhwa_ddi_101_8-9-09.pdf $>$.

Xu, H.; Liu, H.; Tian, Z.; Zhang, W. 2011. Control delay calculation at diverging diamond interchanges, Transportation Research Record: Journal of the Transportation Research Board, 2257: 121-130. 